\title{
Suicide verdicts as opposed to accidental deaths in substance-related fatalities (UK, 2001-2007)
}

\author{
Alessandro E. Vento ${ }^{\text {a,* }}$, Fabrizio Schifano ${ }^{\text {b }}$, John M Corkery ${ }^{\text {c }}$, Maurizio Pompili ${ }^{\text {a,d }}$, Marco \\ Innamorati ${ }^{a}$, Paolo Girardi ${ }^{a}$, and Hamid Ghodse ${ }^{\mathrm{d}}$ \\ ${ }^{a}$ Department of Neurosciences, Mental Health and Sensory Functions, Suicide Prevention Centre, Sant'Andrea \\ Hospital, Sapienza University of Rome, Italy; \\ ${ }^{\mathrm{b}}$ School of Pharmacy, University of Hertfordshire, Hatfield, UK; \\ ${ }^{\mathrm{c}}$ National Programme for Substance Abuse Deaths (np-SAD), International Centre for Drug Policy, 6th floor Hunter \\ Wing, St George's, University of London, Cranmer Terrace, London, UK. \\ ${ }^{\mathrm{d}}$ McLean Hospital, Harvard Medical School, USA;
}

* Corresponding author: Department of Neurosciences, Mental Health and Sensory Functions, Suicide Prevention Centre, Sant'Andrea Hospital, Sapienza University of Rome, Italy. E-mail address: ventoalessandro@ hotmail.com Tel.: +390633775675 
Background: Substance-related deaths account for a great number of suicides.

Aim: To investigate levels and characteristics of suicide verdicts, as opposed to accidental deaths, in substance misusers.

Methods: Psychological autopsy study of cases from the UK National Programme on Substance Abuse Deaths (np-SAD) during the period 2001-2007.

Results: Between January 2001 and December 2007, 2108 suicides were reported to the np-SAD. Typical suicide victims were White and older than 50 (respectively $95 \%$ and $41 \%$ of cases). Medications, especially antidepressants (44\%), were prescribed to $87 \%$ of victims. Significantly fewer suicides than controls presented with positive blood toxicological results for illicit drugs (namely: cocaine, heroin, amphetamines, ecstasy-type drugs, cannabis, GHB/GBL, etc.) and alcohol.

Conclusions: Suicide prevention programmes should devote specific attention to deaths among substance misusers who are at high risk of fatal intentional self-harm. Specific characteristics distinguish those at risk; caregivers should be better educated as to what these factors are. Limitations of the current study included lack of provision of comprehensive information relating to the victims' psychosocial variables. Furthermore, no differentiation between within class different antidepressants in terms of involvement in suicide was here provided. Keywords: Substance Abuse, Suicide, Accidental deaths, United Kingdom, Antidepressants.

Abbreviations: np-SAD, UK National Programme on Substance Abuse Deaths; $\chi 2$, chi-square tests; OR, Odds Ratios. 


\section{Introduction}

Substance misuse is a major cause of disability, and drug-related deaths account for a sizeable percentage of all deaths in this population (Ghodse et al., 2010). Comorbidity between substance abuse and psychiatric disorders is a matter of great concern; both conditions are reportedly linked to increased suicide risk (Ghodse et al., 2009; Harris and Barraclough, 1997; Hawton and van Heeringen, 2009). Findings from the UK confirm that addicts are still at higher risk of suicide than the general population and that prescribed drugs, notably antidepressants and methadone, are associated with a heightened risk (Oyefeso et al., 1999). In the UK, the National Programme on Substance Abuse Deaths (np-SAD; Ghodse et al., 2010), constitutes a strategic observatory of the phenomenon with key strategic opportunities. Although suicide is particularly represented in substance abusers, little is known about the role of psychoactive substances' self administration as a suicidal method.

The aims of the present study were to investigate substance abuse deaths due to suicide and to characterise this population as compared to other causes of death. Using the above-mentioned National Registry we aimed to examine the pattern of all reported overdose suicides in this UK population during a specific time-frame.

\section{Methods}

This 7-year (January 2001 to December 2007) retrospective study reports on cases from the np-SAD, located at St. George's, University of London. The np-SAD was established after the Home Office Addicts Index closed in 1997 and, since then, it has regularly received information from coroners on a voluntary basis on deaths related to drugs in both addicts and non-addicts in England and Wales, Northern Ireland, the Channel Islands and the Isle of Man. Since 2004, information has been received from the Scottish Crime and Drug Enforcement Agency and the General Register Office for Northern Ireland. To date, details of some 23,000 deaths have been received. To be recorded in the np-SAD database as a drug-related death, at least one of the following criteria must be met: (a) presence of one or more psychoactive substances directly 
implicated in death; (b) history of dependence or abuse of drugs; and (c) presence of controlled drugs at post-mortem. Deaths that occurred outside the UK are excluded, so that the information is comparable with the statistics from the UK General Mortality registers. The response rate from coroners in England and Wales during the period examined ranged from $89 \%$ to $95 \%$. However, often further information is submitted eventually and appropriately added to the database, so that the resulting coroners' compliance rates are higher. All cases notified have been included in these analyses.

We selected all consecutive cases of drug-related deaths from the np-SAD database that occurred in the UK between January 2001 and December 2007 and where death was unequivocally classified as suicide by Coroners. Excluded were all presumed suicides for which information was unclear or missing in respect of intention, e.g. no 'suicide note'. Controls were all consecutive cases of drug-related deaths from np-SAD database that died in the UK during the same time-frame, and whose manner of death was classified as accidental by Coroners. A total of 2108 files fulfilling inclusion criteria were retrieved and were selected for the suicide group. Some 4096 files were retrieved and were selected as controls for the study.

The information was gathered through review of medical and social history, post-mortem examination, and toxicological evaluation. We extracted socio-demographic variables (age, gender, ethnicity, employment status, living arrangements), and reports of the presence of drug use disorders, prescribed medication, and psychoactive substances at the toxicological examination. Toxicological analyses were performed on blood, urine, or other matrices. Typical toxicology post mortem screening was for ethanol and other volatiles, as well as for a wide variety of prescription, and illicit drugs commonly used or abused in the UK.

A verdict of suicide requires "some evidence that the deceased intended to take his own life" meaning that open verdicts are often recorded in cases where suicide is suspected but the evidence of intent is lacking. A number of studies reported (Cooper and Milroy, 1995; Lindqvist and Gustafsson, 2002; Linsley et al., 2001; Parai et al., 2006; Platt et al., 1988; Salib, 1996) that deaths 
from hanging and gas were more likely to be assigned as suicide, whereas deaths from poisoning and drowning were less likely to be so assigned.

Chi-square tests with Yates's correction $\left(\chi^{2}\right)$ and one-way Fisher exact tests were used to analyze $\mathrm{N} x \mathrm{~N}$ contingency tables; t-tests were used to analyse differences between groups on dimensional variables. Bonferroni's correction was used to correct for multi-testing. Log-linear modelling analysis was employed to determine multivariate associations between variables significant at the level of bivariate analyses. Because the computing limitation was 9 variables, separate analyses were carried out. Likelihood ratio $\chi^{2}$ as measure of fit of the model; Odds Ratios $(\mathrm{OR})$ and $\log -\mathrm{OR}$ as measure of association are reported here. All statistical analyses were performed using the SPSS ${ }^{\mathrm{TM}}$ for Windows statistical software package Version 13.0.

\section{Results}

Sociodemographic characteristics for the 2108 suicide cases are listed in Table 1. Around $61 \%$ of the suicide victims were males. Suicide victims were aged 13 to 97 years (mean=47.66; $\mathrm{SD}=17.42$ ), and around 95\% were White (where ethnicity was known).

People who died from suicide and controls that died from accidental causes differed on

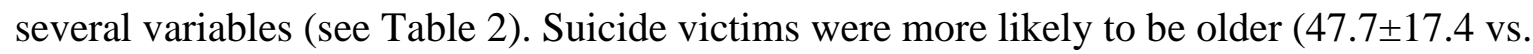
$\left.36.1 \pm 11.9 ; \mathrm{t}_{\mathrm{DF}=3145.92}=27.27 ; \mathrm{p}<0.001\right)$, and female (39\% vs. $\left.22 \% ; \mathrm{p}<0.001\right)$. Furthermore, they differed in terms of both employment status $\left(\chi_{\mathrm{df}=3}^{2}=604.39 ; \mathrm{p}<0.001\right)$, and living arrangements $\left(\chi_{\mathrm{df}=2}^{2}=96.41 ; \mathrm{p}<0.001\right)$. More suicide victims were either retired/invalid/sick $(26.4 \%$ vs. $6.2 \%)$, or employed (36.0\% vs. $30.8 \%)$ than those people whose death was accidental. These results may be associated with the older age of the suicide victims (17.5\% of suicide victims were $65+$ years old vs. only $2.8 \%$ of controls). Also, compared to controls, fewer suicide victims were addicted to illicit drugs (only $29 \%$ vs. $80 \%$; $p<0.001$ ), whilst more suicide victims were prescribed with medications (87\% vs. $70 \% ; \mathrm{p}<0.001)$.

When comparing groups for categories of prescribed psychoactive drugs, groups were different for all categories except for anti-epileptics ( $\mathrm{p}=0.09)$, anti-Parkinson $(\mathrm{p}=0.32)$, and 
amphetamines ( $\mathrm{p}=0.36$; after correction for multi-testing). Suicide victims (compared to accidental deaths) were more likely to have been prescribed hypnotics/sedatives ( $28 \%$ vs. $23 \%$; $p<0.001)$, antidepressants (44\% vs. $20 \%$; $p<0.001)$, antipsychotics (13\% vs. 9\%; $<<0.001)$, and other opiates/opioid analgesics ( $21 \%$ vs. $11 \%$; p < 0.001$)$, and they were less likely to have been prescribed methadone ( $2 \%$ vs. $9 \% ; \mathrm{p}<0.001)$.

When assessing types of prescribed antidepressants, $38.5 \%$ and $26.8 \%$, respectively of suicide victims and accidental deaths were prescribed tricyclic antidepressants $(\mathrm{p}<0.001) ; 39.3 \%$ and $46.2 \% \%$, respectively of suicide victims and accidental deaths were prescribed selective serotonin reuptake inhibitors (SSRIs) $(\mathrm{p}<0.01)$; whilst respectively $16.0 \%$ and $9.9 \%$ of suicide victims and accidental deaths were prescribed venlafaxine $(\mathrm{p}<0.001)$. Conversely, suicide victims and accidental deaths did not differ in terms of prescription rates of the following drugs: inhibitors of monoamino-oxidase (IMAOs); mirtazapine; and trazodone.

When investigating toxicological results (Table 2), groups differed for all categories of substances investigated except for hypnotics/sedatives; anti-epileptics; and anti-Parkinson. More suicide victims than controls had positive toxicological results for antidepressants (38\% vs. 14\%; p<0.001), antipsychotics (6\% vs. $3 \%$; $<<0.001)$, and barbiturates ( $2 \%$ vs. $0.4 \%$; $<<0.001)$; and fewer suicide victims than controls had positive toxicological results for an illicit drug (54\% vs. $76 \%$; $\mathrm{p}<0.001)$, alcohol (25\% vs. $39 \%$; $\mathrm{p}<0.001)$, and methadone (4\% vs. $18 \%$; $\mathrm{p}<0.001)$. In suicide victims, in comparison with accidental deaths, SSRIs were less frequently (respectively: $24.8 \%$ vs $29.5 \% ; \mathrm{p}<0.05)$; and venlafaxine more frequently $(12.9 \%$ vs $9.4 \% ; \mathrm{p}<0.05)$ identified at post mortem toxicological analyses.

To evaluate multivariate associations between variables several log-linear analyses were performed, with the groups (suicide vs. accidental deaths) as the dependent variable, and all the variables significant at the bivariate analyses after correction for multiple testing as independent variables (see Table 3). The first model tested (group x [gender, drug addiction status, age bands, living arrangements, employment status, and the presence or not of any prescribed medication]) 
fitted the data well (Likelihood Ratio $\chi^{2}=243.45$ [DF=372]; $\mathrm{p}=1.00$ ). Suicide victims were 1.4 times more likely to be older adults $(\mathrm{p}<0.05)$ than accidental deaths. They were also more likely to have been prescribed any medication $(\mathrm{OR}=2.2 ; \mathrm{p}<0.001)$, and less likely to be unemployed $(\mathrm{OR}=0.6$; $\mathrm{p}<0.05)$ or to have been formally identified as drug addicts $(\mathrm{OR}=0.1 ; \mathrm{p}<0.001)$, than accidental deaths.

For any single category of drugs prescribed and substances implicated at the toxicological analysis, we performed two independent log-linear analyses, and then all the variables significantly associated with death groups were entered into a final model. The final model fitted the data well (Likelihood Ratio $\chi^{2}=338.93$ [DF=502]; $\mathrm{p}=1.00$ ). Groups differed on all the variables entered; more in particular: a) suicidal victims were more likely to have been prescribed antidepressants $(\mathrm{OR}=1.7$; $\mathrm{p}<0.001)$, and opiates $(\mathrm{OR}=2.4 ; \mathrm{p}<0.001)$, and less likely to have been prescribed hypnotics/sedatives $(\mathrm{OR}=0.8 ; \mathrm{p}<0.05)$, and methadone $(\mathrm{OR}=0.6 ; \mathrm{p}<0.01)$ than accidental deaths; and b) more suicide victims had positive toxicological results for antidepressants ( $O R=1.9$; $\mathrm{p}<0.001)$, and barbiturates $(\mathrm{OR}=3.3 ; \mathrm{p}<0.001)$, and less positive toxicological results for an illicit $\operatorname{drug}(\mathrm{OR}=0.4 ; \mathrm{p}<0.001)$, alcohol $(\mathrm{OR}=0.6 ; \mathrm{p}<0.001)$, and methadone $(\mathrm{OR}=0.2 ; \mathrm{p}<0.001)$ than accidental deaths.

\section{Discussion}

This study sought to characterise suicide among drug-related deaths. Notably, a considerable number of variables significantly identified suicides when compared to other causes of death among substance-related deaths.

Our study identified that specific sociodemographic characteristics are important in identifying suicide victims, as they were more likely to be older and female. More suicide victims had a medical or economic problem than those people whose death was accidental, although this may be partly explained by the older age of the suicide victims.

Also, compared to controls, fewer suicide victims had been formally identified as dependent on illicit drugs, while more suicide victims were prescribed medication. More specifically, suicide 
victims (compared to accidental deaths) were more likely to have been prescribed hypnotic/sedatives, antidepressants, antipsychotics, and other opiates/opioid analgesics, and they were less likely to have been prescribed methadone.

Toxicological results confirmed that more suicide victims than controls were positive for psychotropic drugs, and fewer suicide victims than controls had positive results for illicit drugs, alcohol, and methadone. The higher rate of prescription/positive blood test of psychotropics among suicides than among non suicides may not be considered surprising, as suicides have more frequently psychiatric illness(es). It has been recently confirmed (Isaccson et al, 2010) that antidepressant prescription may well be associated with suicide prevention in depression. Since the length of psychotropic drug treatment before suicide was not made available for the current analysis, one could speculate that most suicide victims with positive blood test of psychotropics were in the early stage of the treatment or were non responders.

Comparing with the higher lethality levels of first generation antidepressants (Beaumont, 1989; Reseland et al., 2006), the introduction of serotonergic agents was reported as a breakthrough in the reduction of suicide rates when drugs were used to precipitate suicide (Grunebaum et al., 2004; Isacsson, 2000). In line with this, and consistent with Cheeta et al (2004) observations in suicide victims, in comparison with accidental deaths, SSRIs were less frequently $(\mathrm{p}<0.05)$; and venlafaxine more frequently $(\mathrm{p}<0.05)$ identified at post mortem toxicological analyses.

In a comprehensive overview of deaths related to analgesic- and cough suppressant-opioids in England and Wales during the period 1996-2002, Schifano et al. (2006) found that most (83\%) addicts died as a result of accidental deaths. Conversely, the number of intentional poisoning cases was considerably high (46\%) in non-addicts. Antidepressant- and dextropropoxyphene-containing compounds were mostly represented in non-addicts' intentional deaths. Dextropropoxyphene was arguably prescribed for pain control and one might hypothesize a possible association between chronic pain and depression, which may in turn have led to suicide (Schifano et al., 2006). Even the psychiatric co-morbidity and antidepressant prescription issues may deserve further investigation in 
accidental deaths (Holding and Barraclough, 1977).

In the past, suicide caused great stigmatisation, and death certification could be left deliberately inaccurate due to the need to conceal the act (Seabourne and Seabourne, 2001). Although stigmatisation towards suicide still exists (Pompili et al., 2003; Pompili et al,, 2004), there is a growing need to report causes of death correctly. Although this may be a controversial issue (Ohberg and Lonnqvist, 1998), in 1978 Holding and Barraclough demonstrated that most undetermined deaths in the UK population were not suicides as previously hypothesized.

Our study has a number of limitations that should be taken into account. Firstly, it did not involve a thorough psychological autopsy approach, which would have added important information about the psychosocial characteristics of the deceased. In fact, a psychological autopsy helps to clarify an equivocal death by interviewing people who knew the deceased individual (spouse, grown children, neighbours, employers, or physicians) and by analysing his/her clinical records. Despite this limitation, the current investigation may still shed some light on both the mechanics and the characteristics of suicidal events in substance misusers. Furthermore, as Hawton and colleagues (2010) recently reported, there are wide differences in toxicity not only between classes of antidepressants but also within classes, therefore future studies should consider the involvement in fatalities of specific molecules, not just of drug classes. Again, levels of blood toxicology results (e.g., low/therapeutic/toxic level) were here unfortunately not always provided by Coroners. Finally, different from the approach taken here, it has been suggested that deaths receiving an 'open' verdict should be included in all suicide research after excluding cases in which suicide was unlikely (Linsley et al, 2001).

It is concluded that suicide prevention programmes should devote specific attention to deaths among substance misusers who are at high risk of fatal intentional self-harm. Specific characteristics may distinguish those at risk; caregivers should be better educated as to what these factors are (Baca-Garcia et al., 2007; Nordentoft, 2010).

Acknowledgements: Authors report no competing interests. 


\section{References}

Baca-Garcia E, Perez-Rodriguez MM, Saiz-Gonzalez D, Basurte-Villamor I, Saiz-Ruiz J, LeivaMurillo JM, et al., 2007. Variables associated with familial suicide attempts in a sample of suicide attempters. Prog Neuropsychopharmacol Biol Psychiatry 31, 1312-6.

Beaumont G, 1989. The toxicity of antidepressants. Br J Psychiatry 154, 454-8.

Cheeta S, Schifano F, Oyefeso A, Webb L, Ghodse AH, 2004. The profile of antidepressant related deaths and antidepressant prescriptions in England and Wales (1998-2000). Br J Psychiatry, 184: $41-47$

Cooper PN, Milroy CM, 1995. The coroner's system and under-reporting of suicide. Med Sci Law $35,319-26$.

Ghodse H, Corkery J, Ahmed K, Naidoo V, Oyefeso A, Schifano F, 2010. Drug-related deaths in the UK: Annual Report 2010. Drug-related deaths reported by Coroners in England, Wales, Northern Ireland, Guernsey, Jersey and the Isle of Man; Police forces in Scotland; \& the Northern Ireland Statistics and Research Agency - Annual Report January-December 2009. International Centre for Drug Policy, St George's University of London, London.

Grunebaum MF, Ellis SP, Li S, Oquendo MA, Mann JJ, 2004. Antidepressants and suicide risk in the United States, 1985-1999. J Clin Psychiatry 65, 1456-62.

Harris EC, Barraclough B, 1997. Suicide as an outcome for mental disorders. A meta-analysis. Br J Psychiatry 170, 205-28.

Hawton K, Bergen H, Simkin S, Cooper J, Waters K, Gunnell D, et al., 2010. Toxicity of antidepressants: rates of suicide relative to prescribing and non-fatal overdose. $\mathrm{Br} \mathbf{J}$ Psychiatry 196, 354-8.

Hawton K, van Heeringen K, 2009. Suicide. Lancet 373, 1372-81.

Holding TA, Barraclough BM, 1977. Psychiatric morbidity in a sample of accidents. Br J Psychiatry 130, 244-52. 
Holding TA, Barraclough BM, 1978. Undetermined deaths-suicide or accident? Br J Psychiatry $133,542-9$.

Isacsson G, 2000. Suicide prevention--a medical breakthrough? Acta Psychiat Scand 102, 113-7.

Isacsson G, Reutfors J, Papadopoulos FC, Osby U, Ahlner J, 2010. Antidepressant medication prevents suicide in depression. Acta Psychiatr Scand 122, 454-6

Lindqvist P, Gustafsson L, 2002. Suicide classification--clues and their use. a study of 122 cases of suicide and undetermined manner of death. Forensic Sci Int 128, 136-40.

Linsley KR, Schapira K, Kelly TP, 2001. Open verdict v. suicide - importance to research. Br J Psychiatry 178, 465-8.

Nordentoft M, 2010. Crucial elements in suicide prevention strategies. Prog Neuropsychopharmacol Biol Psychiatry Dec 2. [Epub ahead of print]

Ohberg A, Lonnqvist J, 1998. Suicides hidden among undetermined deaths. Acta Psychiatr Scand 98, 214-8.

Oyefeso A, Ghodse H, Clancy C, Corkery JM, 1999. Suicide among drug addicts in the UK. Br J Psychiatry 175, 277-82.

Parai JL, Kreiger N, Tomlinson G, Adlaf EM, 2006. The validity of the certification of manner of death by Ontario coroners. Ann Epidemiol 16, 805-11.

Platt S, Backett S, Kreitman N, 1988. Social construction or causal ascription: distinguishing suicide from undetermined deaths. Soc Psychiatry Psychiatr Epidemiol 23, 217-21.

Pompili M, Mancinelli I, Girardi P, Tatarelli R, 2004. Toward better understanding of equivocal deaths and suicides. Croat Med J 45, 103-4.

Pompili M, Mancinelli I, Tatarelli R, 2003. Stigma as a cause of suicide. Br J Psychiatry 183, 1734.

Reseland S, Bray I, Gunnell D, 2006. Relationship between antidepressant sales and secular trends in suicide rates in the Nordic countries. Br J Psychiatry 188, 354-8.

Salib E, 1996. Predictors of coroner's verdict: a logistic regression model. Med Sci Law 36, 237-41. 
Schifano F, Zamparutti G, Zambello F, Oyefeso A, Deluca P, Balestrieri M, et al., 2006. Review of Deaths Related to Analgesic- and Cough Suppressant-opioids; England and Wales 19962002. Pharmacopsychiatry 39, 185-191.

Seabourne A, Seabourne G, 2001. Suicide or accident - self-killing in medieval England: series of 198 cases from the Eyre records. Br J Psychiatry 178, 42-7. 
Table 1

Sociodemographic characteristics of suicide victims

Suicide victims

$\mathbf{N}$

2108

\section{Part of UK where death occurred}

England

$95.6 \%$

Wales

$3.1 \%$

Guernsey

$0.1 \%$

Jersey

$0.9 \%$

Isle of Man

$0.2 \%$

Men

$60.8 \%$

Age - Mean \pm SD

$47.66 \pm 36.13$

\section{Ethnicity}

White

$95.1 \%$

Black Carribean

$0.7 \%$

Black African

$0.6 \%$

Black Other

$0.4 \%$

Indian

$0.7 \%$

Pakistani

$0.6 \%$

Bangladeshi

$0.0 \%$

Chinese

$0.1 \%$

Other

$1.9 \%$ 
Table 2

Differences between groups

\begin{tabular}{|c|c|c|c|c|}
\hline Variables & $\begin{array}{l}\text { Suicide } \\
\text { victims } \\
(\mathrm{N}=\mathbf{2 1 0 8})\end{array}$ & $\begin{array}{l}\text { Accidental } \\
\text { deaths } \\
(\mathrm{N}=4096)\end{array}$ & Test & P-value \\
\hline Males & $60.8 \%$ & $78.4 \%$ & & 0.001 \\
\hline Age & $47.66 \pm 17.42$ & $36.13 \pm 11.90$ & $\mathrm{t}_{\mathrm{DF}=3145.92}=27.27$ & 0.001 \\
\hline Ethnicity & & & $\chi_{\mathrm{df}=8}^{2}=11.54$ & 0.17 \\
\hline White & $95.1 \%$ & $95.1 \%$ & & 0.50 \\
\hline Others & $4.9 \%$ & $4.6 \%$ & & \\
\hline Employment status & & & $\chi_{\mathrm{df}=3}^{2}=604.39$ & 0.001 \\
\hline Unemployed & $32.1 \%$ & $58.5 \%$ & & \\
\hline Employed & $36.0 \%$ & $30.8 \%$ & & \\
\hline Retired/invalidity/sickness & $26.4 \%$ & $6.2 \%$ & & \\
\hline Other & $5.5 \%$ & $4.5 \%$ & & \\
\hline Living arrangements & & & $\chi_{\mathrm{df}=2}^{2}=96.41$ & 0.001 \\
\hline With others & $47.3 \%$ & $48.1 \%$ & & \\
\hline Alone & $48.5 \%$ & $40.5 \%$ & & \\
\hline Other & $4.2 \%$ & $11.4 \%$ & & \\
\hline Drug addiction & $28.7 \%$ & $79.7 \%$ & & 0.001 \\
\hline Prescribed medication & $87.4 \%$ & $69.8 \%$ & & 0.001 \\
\hline Hypnotics/sedatives & $28.1 \%$ & $23.4 \%$ & & 0.001 \\
\hline Antidepressants & $43.6 \%$ & $19.5 \%$ & & 0.001 \\
\hline Antipsychotics & $13.1 \%$ & $9.2 \%$ & & 0.001 \\
\hline Antiepileptics & $5.3 \%$ & $4.5 \%$ & & 0.09 \\
\hline
\end{tabular}




\begin{tabular}{|c|c|c|c|}
\hline Anti-Parkinsons & $1.6 \%$ & $1.4 \%$ & 0.32 \\
\hline Heroin/morphine & $2.5 \%$ & $1.6 \%$ & 0.009 \\
\hline Other opiates/opioid analgesics & $21.4 \%$ & $11.2 \%$ & 0.001 \\
\hline Methadone & $2.3 \%$ & $9.2 \%$ & 0.001 \\
\hline Amphetamines & $0.1 \%$ & $0.2 \%$ & 0.36 \\
\hline \multicolumn{4}{|c|}{ Positive blood toxicological results for } \\
\hline Any illicit drug & $53.8 \%$ & $76.3 \%$ & 0.001 \\
\hline Alcohol & $25.4 \%$ & $38.6 \%$ & 0.001 \\
\hline Methadone & $3.5 \%$ & $17.9 \%$ & 0.001 \\
\hline Antidepressants & $37.6 \%$ & $13.7 \%$ & 0.001 \\
\hline Hypnotics/sedatives & $22.1 \%$ & $21.3 \%$ & 0.27 \\
\hline Antipsychotics & $5.5 \%$ & $2.7 \%$ & 0.001 \\
\hline Antiepileptics & $2.8 \%$ & $1.7 \%$ & 0.005 \\
\hline Anti-Parkinsons & $0.5 \%$ & $0.5 \%$ & 0.46 \\
\hline Barbiturates & $1.5 \%$ & $0.4 \%$ & 0.001 \\
\hline
\end{tabular}

Multi-testing correction: Bonferroni p-value $=0.10 / 25=0.004$ 
Table 3

Loglinear Models

\begin{tabular}{|c|c|c|c|c|}
\hline \multirow[t]{2}{*}{ Model } & \multirow[t]{2}{*}{ Parameter } & \multicolumn{3}{|c|}{ Log- } \\
\hline & & OR & OR & $\mathbf{P}<$ \\
\hline \multirow[t]{11}{*}{1} & Suicide victims $*$ Men & 1.00 & 0.004 & 0.97 \\
\hline & Suicide victims * Drug addiction & 0.14 & -1.94 & 0.001 \\
\hline & Suicide victims $*$ Adolescents & 0.69 & -0.37 & 0.48 \\
\hline & Suicide victims * Young Adults ( $<35$ years old) & 0.79 & -0.24 & 0.01 \\
\hline & Suicide victims $*$ Older adults $(65+$ years old $)$ & 1.41 & 0.35 & 0.05 \\
\hline & Suicide victims $*$ Living with others & 1.19 & 0.18 & 0.35 \\
\hline & Suicide victims $*$ Living alone & 1.31 & 0.27 & 0.15 \\
\hline & Suicide victims * Unemployed & 0.62 & -0.48 & 0.05 \\
\hline & Suicide victims * Employed & 1.17 & 0.16 & 0.43 \\
\hline & Suicide victims $*$ Retired/invalidity/sickness & 1.22 & 0.20 & 0.37 \\
\hline & Suicide victims * Prescribed medication & 2.23 & 0.80 & 0.001 \\
\hline \multirow[t]{5}{*}{2} & $\begin{array}{l}\text { Suicide victims * Positive blood toxicological results } \\
\text { for any illicit drug }\end{array}$ & 0.39 & -0.93 & 0.001 \\
\hline & $\begin{array}{l}\text { Suicide victims * Positive blood toxicological results } \\
\text { for Alcohol }\end{array}$ & 0.55 & -0.61 & 0.001 \\
\hline & $\begin{array}{l}\text { Suicide victims * Positive blood toxicological results } \\
\text { for Antidepressants }\end{array}$ & 2.61 & 0.96 & 0.001 \\
\hline & $\begin{array}{l}\text { Suicide victims } * \text { Positive blood toxicological results } \\
\text { for Antipsychotics }\end{array}$ & 1.08 & 0.08 & 0.60 \\
\hline & Suicide victims * Positive blood toxicological results & 3.03 & 1.11 & 0.001 \\
\hline
\end{tabular}


for Barbiturates

Suicide victims * Positive blood toxicological results

for Methadone

$\begin{array}{lll}0.14 & -1.97 & 0.001\end{array}$

$3 \quad$ Suicide victims * Antidepressants prescribed

2.97

$1.09 \quad 0.001$

Suicide victims * Antipsychotics prescribed

1.16

$0.15 \quad 0.11$

Suicide victims * Hypnotics/sedatives prescribed

0.87

$-0.14 \quad 0.05$

Suicide victims * Methadone prescribed

0.29

$-1.240 .001$

Suicide victims * Opiates prescribed

1.84

0.610 .001

4

Suicide victims * Positive blood toxicological results

for any illicit drug

$-1.05$

0.001

Suicide victims * Positive blood toxicological results

$-0.57$

0.001

for Alcohol

1.91

0.65

0.001

for Antidepressants

Suicide victims * Positive blood toxicological results

for Barbiturates

$\begin{array}{lll}0.17 & -1.75 & 0.001\end{array}$

for Methadone

Suicide victims * Positive blood toxicological results

for Antidepressants

Suicide victims * Positive blood toxicological results

for Hypnotics/sedatives

$\begin{array}{lll}0.84 & -0.18 & 0.05\end{array}$

Suicide victims * Positive blood toxicological results

for Methadone 


\section{for Opiates}

\begin{tabular}{lccc}
\hline Models fit statistics & Likelihood & DF & P< \\
& Ratio $\chi^{2}$ & & \\
1 & 243.45 & 372 & 1.00 \\
2 & & 57 & 0.22 \\
3 & 65.10 & 26 & 0.001 \\
4 & 101.80 & 2302 & 1.00 \\
\hline
\end{tabular}

